\title{
Synthesis of Cobalt-Encapsulated Carbon Nanocapsules Using Cobalt-Doped Fullerene Nanowhiskers
}

\author{
Daisuke Matsuura, ${ }^{1}$ Kun'ichi Miyazawa, ${ }^{2}$ and Tokushi Kizuka ${ }^{1}$ \\ ${ }^{1}$ Institute of Materials Science, Graduate School of Pure and Applied Sciences, University of Tsukuba, \\ Ibaraki Tsukuba, 305-8753, Japan \\ ${ }^{2}$ Fullerene Engineering Group, Advanced Materials Processing Unit, National Institute for Materials Science, \\ Namiki, Ibaraki Tsukuba, 305-0044, Japan \\ Correspondence should be addressed to Tokushi Kizuka, kizuka@ims.tsukuba.ac.jp
}

Received 24 December 2011; Accepted 11 January 2012

Academic Editors: C. S. Casari and Y. Song

Copyright ( $) 2012$ Daisuke Matsuura et al. This is an open access article distributed under the Creative Commons Attribution License, which permits unrestricted use, distribution, and reproduction in any medium, provided the original work is properly cited.

\begin{abstract}
We synthesized cobalt- (Co-) doped $\mathrm{C}_{60}$ nanowhiskers (NWs) by applying a liquid-liquid interfacial precipitation method using a $\mathrm{C}_{60}$-saturated toluene solution and 2-propanol with Co nitrate hexahydrate $\left(\mathrm{Co}\left(\mathrm{NO}_{3}\right)_{3} \cdot 6 \mathrm{H}_{2} \mathrm{O}\right)$. Heating the NWs at $873-1173 \mathrm{~K}$ produced carbon nanocapsules (CNCs) that encapsulated Co clusters with a hexagonal-closed-packed structure. After heating at $1273 \mathrm{~K}$, the encapsulated Co clusters in $\mathrm{CNCs}$ were transformed into orthorhombic $\mathrm{Co}_{2} \mathrm{C}$ clusters. It was found that Co- and $\mathrm{Co}_{2} \mathrm{C}$-encapsulated $\mathrm{CNCs}$ can be produced by varying heating temperature.
\end{abstract}

\section{Introduction}

Carbon nanocapsules (CNCs), which are hollow multiwalled graphitic nanoparticles, exhibit high chemical and thermal stabilities [1-8]. The encapsulation of metallic and carbide clusters in CNCs leads to the formation of catalysts and drug delivery components $[4,9-17]$. Such pristine and encapsulated CNCs have been synthesized by arc discharge, chemical vapor deposition, electron irradiation, and thermal decomposition $[1,3-5,9,11,13-15]$. Recently, a new synthesis method for CNCs using single-crystal fullerene nanowhiskers (NWs) has been developed by Asaka et al. and Kizuka et al. [18-22]. Fullerene NWs have been synthesized by liquid-liquid interfacial precipitation (LLIP) methods. Metal elements can be doped in fullerene NWs using $\mathrm{C}_{60}$ derivatives and additives in solutions [23-31]. It is expected that the alloying of $\mathrm{CNCs}$ and metals can be performed using such metal-doped fullerene NWs. Some of magnetic materials, for example, cobalt (Co) and iron, form solid solutions with carbon. It is expected that various systems with crystal structures, solid solutions, and intermetallics are combined with CNCs. In this study, we demonstrate the synthesis of Co-doped $\mathrm{C}_{60}$ NWs and CNCs encapsulating Co-based clusters.

\section{Method}

We synthesized Co-doped $\mathrm{C}_{60}$ NWs using the LLIP method [25-27]. $\mathrm{C}_{60}$ powders were dissolved in toluene to prepare a $\mathrm{C}_{60}$-saturated solution with a solubility of $2.8 \mathrm{~g} / \mathrm{L}$. Co nitrate hexahydrate $\left(\mathrm{Co}\left(\mathrm{NO}_{3}\right)_{3} \cdot 6 \mathrm{H}_{2} \mathrm{O}\right)$ was dissolved in 2-propanol. The $\mathrm{C}_{60}$ toluene solution was poured into a glass vial, and the 2-propanol dissolving $\mathrm{Co}\left(\mathrm{NO}_{3}\right)_{3} \cdot 6 \mathrm{H}_{2} \mathrm{O}$ was then added to form a liquid-liquid interface. After the vial was maintained at $278 \mathrm{~K}$ for one week, the solution was filtered to extract precipitates. The precipitates were dried and heated in high vacuum at $773-1273 \mathrm{~K}$ for $1 \mathrm{~h}$. The rate of temperature increase was $10 \mathrm{~K} / \mathrm{min}$. The cooling of the specimens was performed by furnace cool. After cooling, the specimens were dispersed on microgrids and observed by transmission electron microscopy.

\section{Results and Discussion}

Figure 1 shows a bright field image of an as-precipitated $\mathrm{C}_{60} \mathrm{NW}$. The diameter of as-precipitated $\mathrm{C}_{60}$ NWs ranged from 190 to $940 \mathrm{~nm}$ with an average of $440 \mathrm{~nm}$. Electron diffraction showed that the NWs had a tetragonal lattice. The surfaces of the Co-doped NWs are porous, as shown 
in Figure 1. This feature is similar to Ni-doped NWs [31], whereas pure $\mathrm{C}_{60}$ NWs are surrounded by plane surfaces [2527]. Miyazawa and Suga used $\mathrm{C}_{60}$ derivatives in LLIP methods and showed that the crystal growth of $\mathrm{C}_{60}$-derivative NWs is inhibited [29]. Therefore, the porous surfaces of the as-precipitated NWs in this study are attributed to the addition of $\mathrm{Co}\left(\mathrm{NO}_{3}\right)_{3} \cdot 6 \mathrm{H}_{2} \mathrm{O}$. No Co clusters were observed in the as-precipitated NWs, indicating that the doped Co component is mixed with atomic states in the NWs.

After heating the as-precipitated specimens at $773 \mathrm{~K}$, the shape of the NWs was similar to that of the as-precipitated specimen. After heating at $873 \mathrm{~K}$, the structure of a portion of the NWs was transformed from a tetragonal to an amorphous form. After heating at temperatures higher than $973 \mathrm{~K}$, all NWs were transformed into amorphous forms, and CNCs were observed in the amorphous regions.

Figure 2(a) shows a high-resolution image of a CNC in the specimen heated at $1073 \mathrm{~K}$. The outer graphitic layers of the $\mathrm{CNC}$ were three-dimensionally closed, and a cluster was encapsulated. As shown in Figure 2(b), selected-area electron diffraction showed that the encapsulated clusters were Co crystals with a hexagonal-closed-packed (hcp) structure having lattice constants of $a=0.25 \mathrm{~nm}$ and $c$ $=0.40 \mathrm{~nm}$. The diameter of the CNCs ranged from 14 to $76 \mathrm{~nm}$ with an average of $35 \mathrm{~nm}$. The diameter of the encapsulated Co clusters ranged from 10 to $44 \mathrm{~nm}$ with an average of $20 \mathrm{~nm}$. Figure 2(c) shows the enlarged interface between the encapsulated Co cluster and the graphitic layers in the Co-encapsulated CNC depicted in Figure 2(a). The Co cluster directly bonded with the graphitic layers. The lattice spacing of the Co cluster and the graphitc layers depicted in Figure 2(b) were $0.20 \mathrm{~nm}$ and $0.34 \mathrm{~nm}$, respectively, corresponding to $(0 \overline{1} 1)$ of hcp-Co and (002) of graphitic layers, respectively. In the specimens heated at $873-1173 \mathrm{~K}$, Co-encapsulated CNCs were observed. Figure 3 shows the thickness of the graphitic layers in Co-encapsulated CNCs produced by heating at $1073 \mathrm{~K}$ against the diameter of the Co clusters. The diameter of the Co clusters ranges from $10 \mathrm{~nm}$ to $45 \mathrm{~nm}$. The maximum thickness of the graphitic layers is $20 \mathrm{~nm}$. In Figure 3, although no clear relationship is observed, the graphitic layers seem to increase with the diameter of the Co clusters. If the graphitic layers were formed by deposition of decomposed carbon atoms on the surfaces of the Co clusters, the thickness of the graphitic layers becomes constant with the diameter of the Co clusters at a certain temperature. On the other hand, if the graphitic layers were formed by simple precipitation from the Co clusters, the thickness of the graphitic layers is proportional to the volume of the Co clusters, that is, the cube of the diameter. Thus, the distribution in Figure 3 suggests that the precipitation of carbon atoms from the Co clusters contributes to the formation of the graphitic layers.

Figure 4(a) shows a high-resolution image of CNCs in the specimen heated at $1273 \mathrm{~K}$. As was the case with the specimens heated at $1073 \mathrm{~K}$, the graphitic layers of the CNCs were closed. Selected-area electron diffraction revealed that the encapsulated clusters were $\mathrm{Co}_{2} \mathrm{C}$ crystals with an orthorhombic lattice with lattice constants of $a$ $=0.47 \mathrm{~nm}, b=0.44 \mathrm{~nm}$, and $c=0.33 \mathrm{~nm}$, as shown in

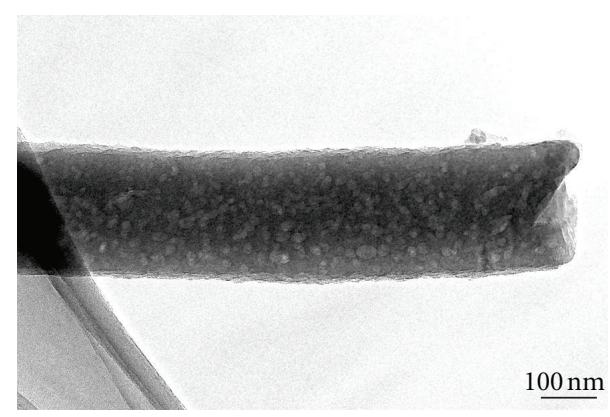

Figure 1: Bright field image of as-precipitated Co-dope $\mathrm{C}_{60}$ nanowhisker. The diameter is $230 \mathrm{~nm}$.

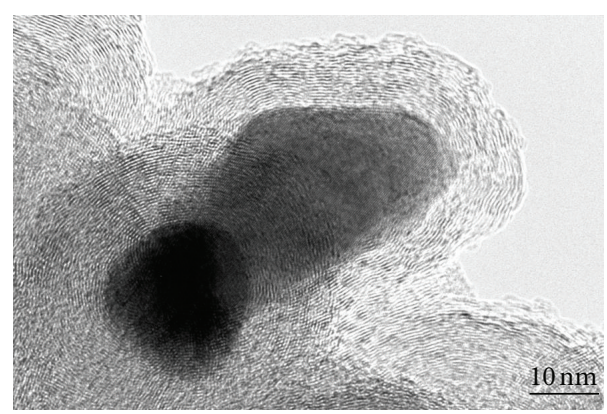

(a)

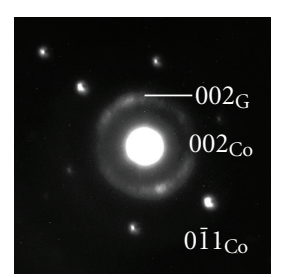

(b)

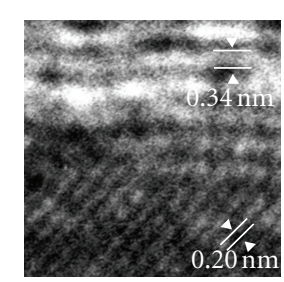

(c)
FIGURE 2: (a) High-resolution image, (b) selected-area electron diffraction pattern of Co-encapsulated carbon nanocapsule in specimen heated at $1073 \mathrm{~K}$. (c) high-resolution image of interface between encapsulated Co cluster and graphitic layers in Coencapsulated carbon nanocapsule depicted in (a).

Figure 4(b). The lattice spacing of the $\mathrm{Co}_{2} \mathrm{C}$ cluster and graphitic layers observed in Figure 4(c) were $0.17 \mathrm{~nm}$ and $0.34 \mathrm{~nm}$, respectively, corresponding to $(1 \overline{2} 1)$ of $\mathrm{Co}_{2} \mathrm{C}$ and (002) of graphitic layers, respectively. In the specimens heated at $1273 \mathrm{~K}$, the diameter of the CNCs ranged from 44 to $66 \mathrm{~nm}$ with an average of $54 \mathrm{~nm}$. In addition, the diameter of the $\mathrm{Co}_{2} \mathrm{C}$ clusters ranged from 29 to $34 \mathrm{~nm}$ with an average of $32 \mathrm{~nm}$. These diameters are larger than those of the specimens heated at $1073 \mathrm{~K}$.

Figure 5 shows the changes in the diameters of both CNCs and encapsulated clusters and in the thickness of the graphitic layers in encapsulated CNCs against the heating temperature. Both the diameters and thickness increase with heating temperature.

The synthesis process for encapsulated CNCs is explained as follows. First, Co atoms that were doped by the addition of $\mathrm{Co}\left(\mathrm{NO}_{3}\right)_{3} \cdot 6 \mathrm{H}_{2} \mathrm{O}$ in the NWs aggregated to form Co clusters 


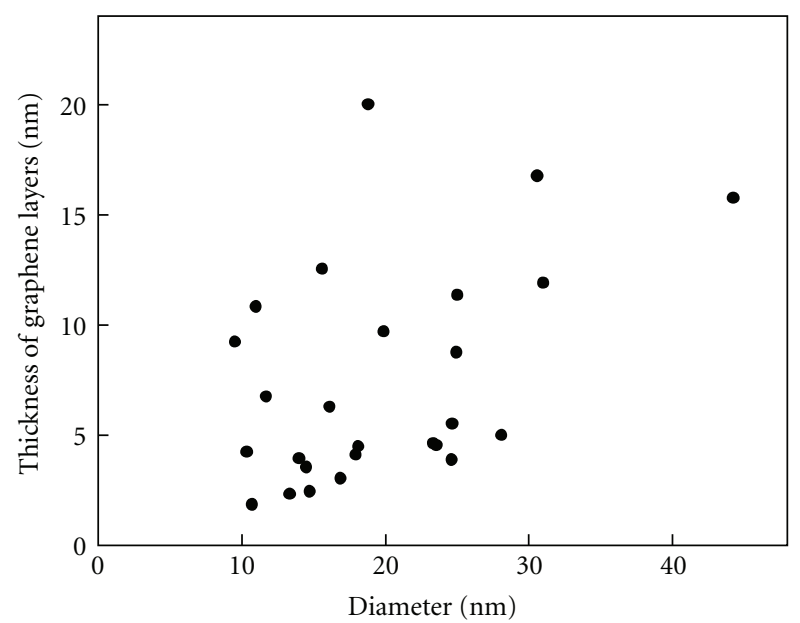

Figure 3: Variation in the thickness of graphitic layers with the diameter of Co clusters in Co-encapsulated carbon nanocapsules prepared by heating at $1073 \mathrm{~K}$.

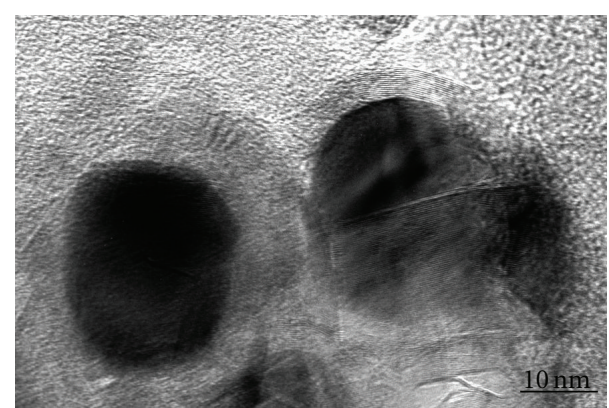

(a)

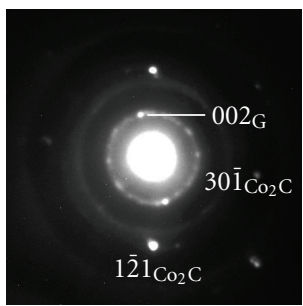

(b)

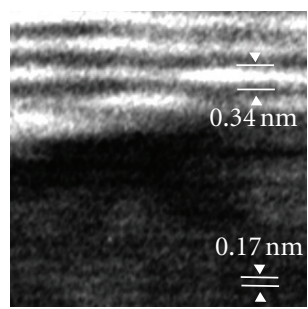

(c)
Figure 4: (a) High-resolution image, (b) selected-area electron diffraction pattern of $\mathrm{Co}_{2} \mathrm{C}$-encapsulated carbon nanocapsule in the specimen heated at $1273 \mathrm{~K}$, (c) High-resolution image of the interface between the encapsulated $\mathrm{Co}_{2} \mathrm{C}$ cluster and the graphitic layers in $\mathrm{Co}_{2} \mathrm{C}$-encapsulated carbon nanocapsule depicted in (a).

by heating around $873 \mathrm{~K}$. Subsequently, $\mathrm{C}_{60}$ molecules in the NWs decomposed at temperatures higher than $873 \mathrm{~K}$. This temperature is lower than that at which pure $\mathrm{C}_{60}$ molecules decompose (1073-1173 K) [32]. Hence, in the present NWs, it is inferred that the Co clusters acted as catalysts that decrease the decomposition temperature of $\mathrm{C}_{60}$ molecules. Such decomposed carbon atoms dissolved in the Co clusters during heating. Then, during cooling, carbon atoms precipitated on the surfaces of the Co clusters, followed by the formation of graphitic layers, that is, Co-encapsulated

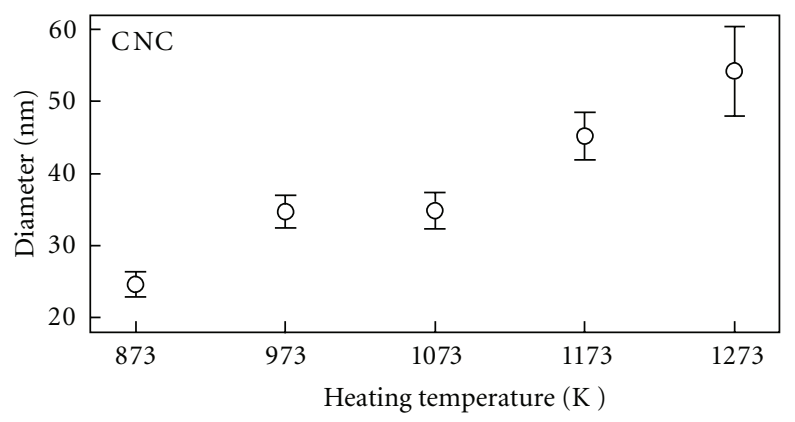

(a)

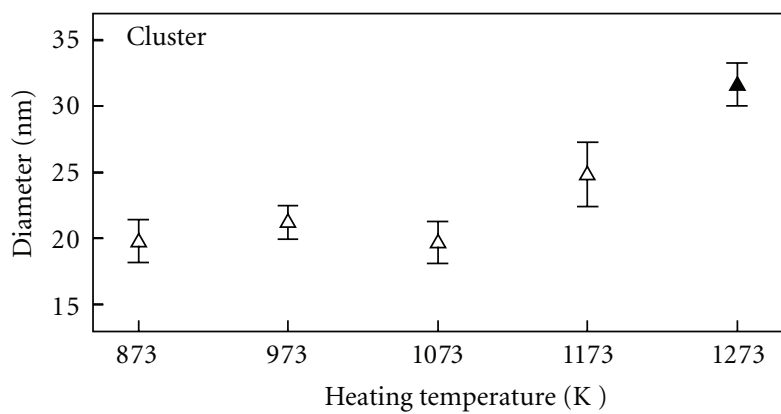

(b)

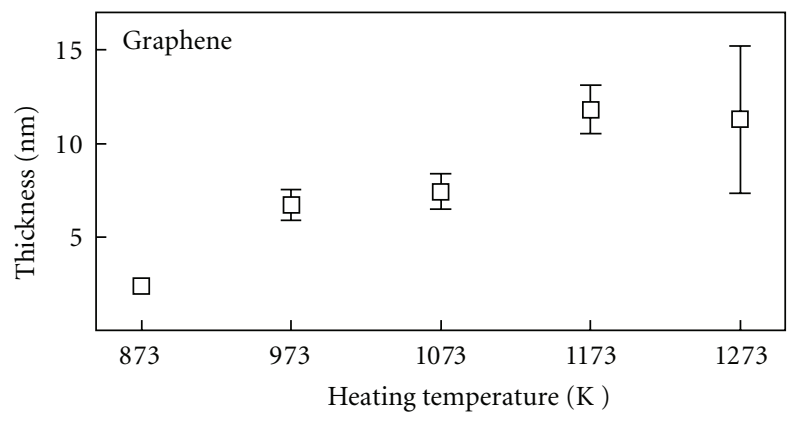

(c)

Figure 5: Variation in the diameter of the carbon nanocapsules and the encapsulated clusters and the thickness of graphitic layers in Coencapsulated carbon nanocapsules with heating temperature. The encapsulated clusters are hexagonal-closed-packed Co (the open triangles in the middle frame) at $873-1173 \mathrm{~K}$ and orthorhombic $\mathrm{Co}_{2} \mathrm{C}$ (the filled triangles in the middle frame) at $1273 \mathrm{~K}$.

CNCs. At higher heating temperatures (1273 K), more C atoms dissolved in the clusters because of increase in the solubility limit. As a result, the $\mathrm{Co}_{2} \mathrm{C}$ clusters were formed after cooling from $1273 \mathrm{~K}$.

\section{Conclusion}

We successfully synthesized Co-doped $\mathrm{C}_{60}$ NWs using the liquid-liquid interfacial precipitation method with the additive $\mathrm{Co}\left(\mathrm{NO}_{3}\right)_{3} \cdot 6 \mathrm{H}_{2} \mathrm{O}$ in 2-propanol. Electron microscopy directly showed that $\mathrm{Co}-$ and $\mathrm{Co}_{2} \mathrm{C}$-encapsulated $\mathrm{CNCs}$ were produced by heating the NWs. It was found that the formation of $\mathrm{Co}-$ and $\mathrm{Co}_{2} \mathrm{C}$-encapsulated $\mathrm{CNCs}$ can be controlled by varying the heating temperature. 


\section{Acknowledgment}

This study was partly supported by Grants-in-Aid from the Ministry of Education, Culture, Sport, Science, and Technology, Japan (nos. 22310065 and 23651127).

\section{References}

[1] R. D. Heidenreich, W. M. Hess, and L. L. Ban, "A test object and criteria for high resolution electron microscopy," Journal of Applied Crystallography, vol. 1, no. 1, pp. 1-19, 1968.

[2] D. Ugarte, "Curling and closure of graphitic networks under electron-beam irradiation," Nature, vol. 359, no. 6397, pp. 707-709, 1992.

[3] Y. Saito, T. Yoshikawa, M. Inagaki, M. Tomita, and T. Hayashi, "Growth and structure of graphitic tubules and polyhedral particles in arc-discharge," Chemical Physics Letters, vol. 204, no. 3-4, pp. 277-282, 1993.

[4] Y. Saito, "Nanoparticles and filled nanocapsules," Carbon, vol. 33, no. 7, pp. 979-988, 1995.

[5] V. Z. Mordkovich, A. G. Umnov, T. Inoshita, and M. Endo, "The observation of multiwall fullerenes in thermally treated laser pyrolysis carbon blacks," Carbon, vol. 37, no. 11, pp. 1855-1858, 1999.

[6] J. S. Yu, S. B. Yoon, Y. J. Lee, and K. B. Yoon, "Fabrication of bimodal porous silicate with silicalite-1 core/mesoporous shell structures and synthesis of nonspherical carbon and silica nanocases with hollow core/mesoporous shell structures," The Journal of Physical Chemistry B, vol. 109, no. 15, pp. 70407045, 2005.

[7] Z. Li, M. Jaroniec, P. Papakonstantinou et al., "Supercritical fluid growth of porous carbon nanocages," Chemistry of Materials, vol. 19, no. 13, pp. 3349-3354, 2007.

[8] J. N. Wang, L. Zhang, J. J. Niu et al., "Synthesis of high surface area, water-dispersible graphitic carbon nanocages by an in situ template approach," Chemistry of Materials, vol. 19, no. 3, pp. 453-459, 2007.

[9] R. S. Ruoff, D. C. Lorents, B. Chan, R. Malhotra, and S. Subramoney, "Single crystal metals encapsulated in carbon nanoparticles," Science, vol. 259, no. 5093, pp. 346-348, 1993.

[10] Y. Saito, T. Yoshikawa, M. Okuda et al., "Carbon nanocapsules encaging metals and carbides," Journal of Physics and Chemistry of Solids, vol. 54, no. 12, pp. 1849-1860, 1993.

[11] M. Tomita, Y. Saito, and T. Hayashi, " $\mathrm{LaC}_{2}$ encapsulated in graphite nano-particle," Japanese Journal of Applied Physics, vol. 32, no. 2B, pp. L280-L282, 1993.

[12] T. Hihara, H. Onodera, K. Sumiyama et al., "Magnetic properties of iron in nanocapsules," Japanese Journal of Applied Physics, vol. 33, no. 1A, pp. L24-L25, 1994.

[13] Y. Saito, K. Nishikubo, K. Kawabata, and T. Matsumoto, "Carbon nanocapsules and single-layered nanotubes produced with platinum-group metals ( $\mathrm{Ru}, \mathrm{Rh}, \mathrm{Pd}, \mathrm{Os}, \mathrm{Ir}, \mathrm{Pt})$ by arc discharge," Journal of Applied Physics, vol. 80, no. 5, pp. 30623067, 1996.

[14] F. Banhart, P. Redlich, and P. M. Ajayan, "Irradiation effects in carbon nanostructures," Chemical Physics Letters, vol. 292, no. 4-6, pp. 554-560, 1998.

[15] F. Banhart, "Irradiation effects in carbon nanostructures," Reports on Progress in Physics, vol. 62, no. 8, pp. 1181-1221, 1999.

[16] A. Vinu, M. Miyahara, V. Sivamurugan, T. Mori, and K. Ariga, "Large pore cage type mesoporous carbon, carbon nanocage: a superior adsorbent for biomaterials," Journal of Materials Chemistry, vol. 15, no. 48, pp. 5122-5127, 2005.
[17] K. Ariga, A. Vinu, M. Miyahara, J. P. Hill, and T. Mori, "Onepot separation of tea components through selective adsorption on pore-engineered nanocarbon, carbon nanocage," Journal of the American Chemical Society, vol. 129, no. 36, pp. 1102211023, 2007.

[18] K. Asaka, R. Kato, Y. Maezono, R. Yoshizaki, K. Miyazawa, and T. Kizuka, "Light-emitting filaments composed of nanometersized carbon hollow capsules," Applied Physics Letters, vol. 88, no. 5, Article ID 051914, 3 pages, 2006.

[19] K. Asaka, R. Kato, K. Miyazawa, and T. Kizuka, "Deformation of multiwalled nanometer-sized carbon capsules," Applied Physics Letters, vol. 89, no. 19, Article ID 191914, 3 pages, 2006.

[20] K. Asaka, R. Kato, R. Yoshizaki, K. Miyazawa, and T. Kizuka, "Conductance of carbon nanocapsule junctions," Physical Review B, vol. 76, no. 11, Article ID 113404, 2007.

[21] T. Kizuka, R. Kato, and K. Miyazawa, "Structure of hollow carbon nanocapsules synthesized by resistive heating," Carbon, vol. 47, no. 1, pp. 138-144, 2009.

[22] T. Kizuka, R. Kato, and K. Miyazawa, "Surface breakdown dynamics of carbon nanocapsules," Nanotechnology, vol. 20, no. 10, Article ID 105205, 2009.

[23] K. Miyazawa, A. Obayashi, and M. Kuwabara, " $\mathrm{C}_{60}$ nanowhiskers in a mixture of lead zirconate titanate sol- $\mathrm{C}_{60}$ toluene solution," Journal of the American Ceramic Society, vol. 84, no. 3-12, pp. 3037-3039, 2001.

[24] K. Miyazawa, " $\mathrm{C}_{70}$ nanowhiskers fabricated by forming liquid/liquid interfaces in the systems of toluene solution of $\mathrm{C}_{70}$ and isopropy/alcohol," Journal of the American Ceramic Society, vol. 85, no. 5, pp. 1297-1299, 2002.

[25] K. Miyazawa, Y. Kuwasaki, A. Obayashi, and M. Kuwabara, " $\mathrm{C}_{60}$ nanowhiskers formed by the liquid-liquid interfacial precipitation method," Journal of Materials Research, vol. 17, no. 1, pp. 83-88, 2002.

[26] K. Miyazawa, K. Hamamoto, S. Nagata, and T. Suga, "Structural investigation of the $\mathrm{C}_{60} / \mathrm{C}_{70}$ whiskers fabricated by forming liquid-liquid interfaces of toluene with dissolved $\mathrm{C}_{60} / \mathrm{C}_{70}$ and isopropyl alcohol," Journal of Materials Research, vol. 18, no. 5, pp. 1096-1103, 2003.

[27] K. Miyazawa, Y. Kuwasaki, K. Hamamoto, S. Nagata, A. Obayashi, and M. Kuwabara, "Structural characterization of $\mathrm{C}_{60}$ nanowhiskers formed by the liquid/liquid interfacial precipitation method," Surface and Interface Analysis, vol. 35, no. 1, pp. 117-120, 2003.

[28] K. Miyazawa, T. Mashino, and T. Suga, "Structural characterization of the $\mathrm{C}_{60}\left[\mathrm{C}\left(\mathrm{COOC}_{2} \mathrm{H}_{5}\right)_{2}\right]$ whiskers prepared by the liquid-liquid interfacial precipitation method," Journal of Materials Research, vol. 18, no. 11, pp. 2730-2735, 2003.

[29] K. Miyazawa and T. Suga, "Transmission electron microscopy investigation of fullerene nanowhiskers and needle-like precipitates formed by using $\mathrm{C}_{60}$ and $\left(\eta^{2}-\mathrm{C}_{60}\right) \mathrm{Pt}\left(\mathrm{PPh}_{3}\right)_{2}$," Journal of Materials Research, vol. 19, no. 8, pp. 2410-2414, 2004.

[30] K. Miyazawa and T. Suga, "Transmission electron microscopy investigation of tubular and capsular needlelike crystals of $\mathrm{C}_{60}$ produced by the liquid-liquid interfacial precipitation method," Journal of Materials Research, vol. 19, no. 11, pp. 3145-3148, 2004.

[31] M. Sathish, K. Miyazawa, and T. Sasaki, "Preparation and characterization of Ni incorporated fullerene nanowhiskers," Diamond and Related Materials, vol. 17, no. 4-5, pp. 571-575, 2008.

[32] S. D. Leifer, D. G. Goodwin, M. S. Anderson, and J. R. Anderson, "Thermal decomposition of a fullerene mix," Physical Review B, vol. 51, no. 15, pp. 9973-9978, 1995. 

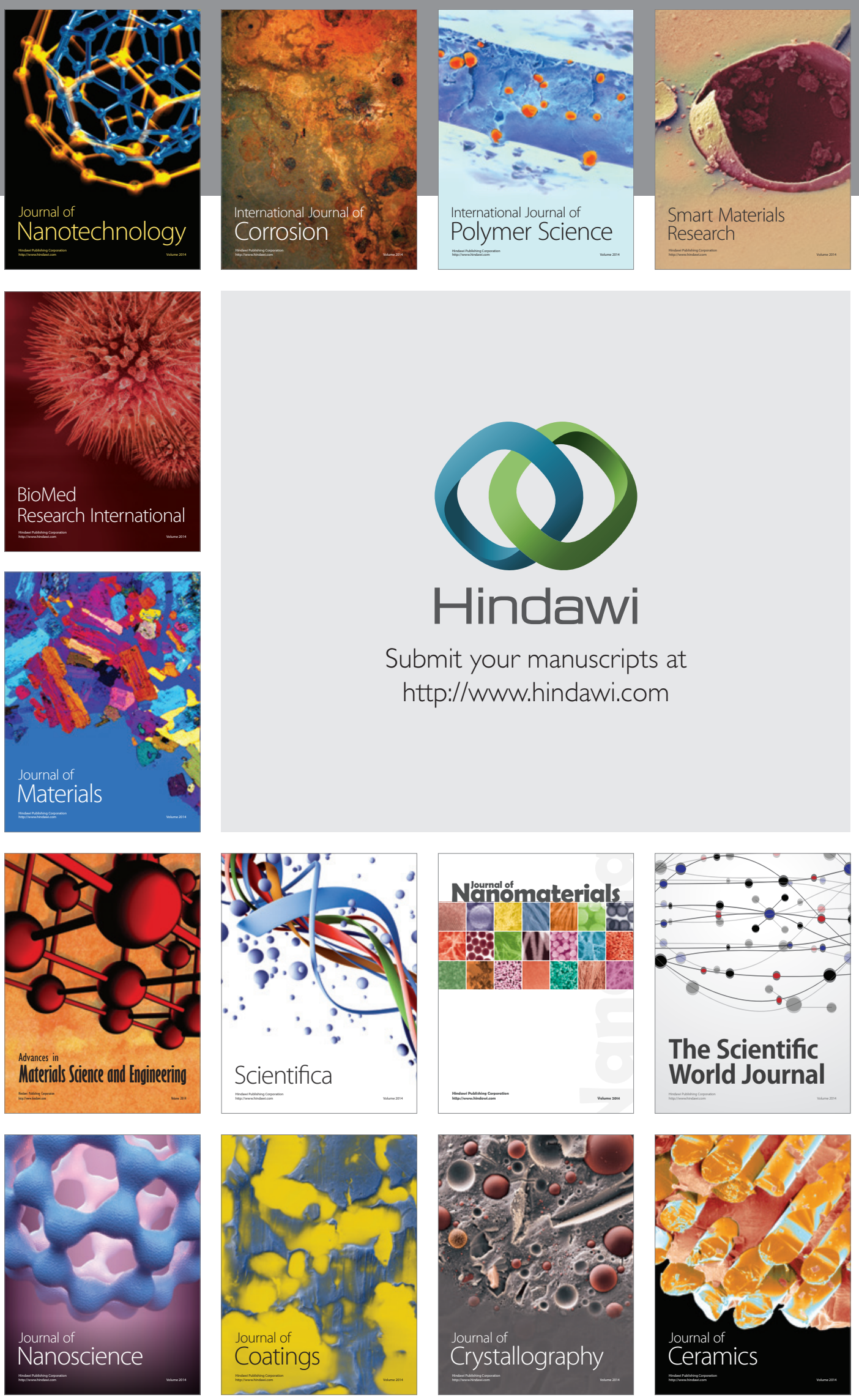

The Scientific World Journal

Submit your manuscripts at

http://www.hindawi.com

\section{World Journal}

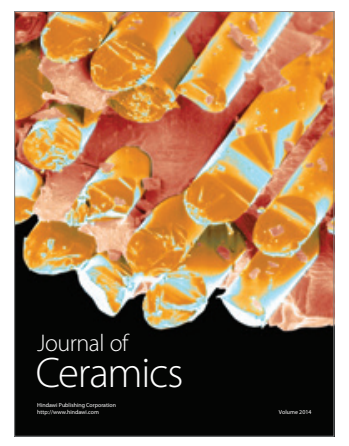

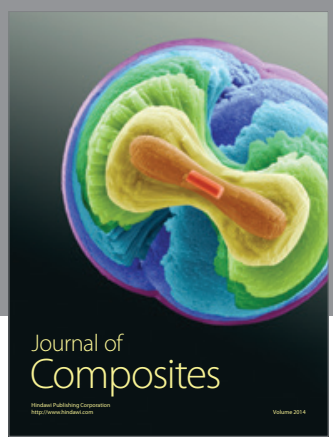
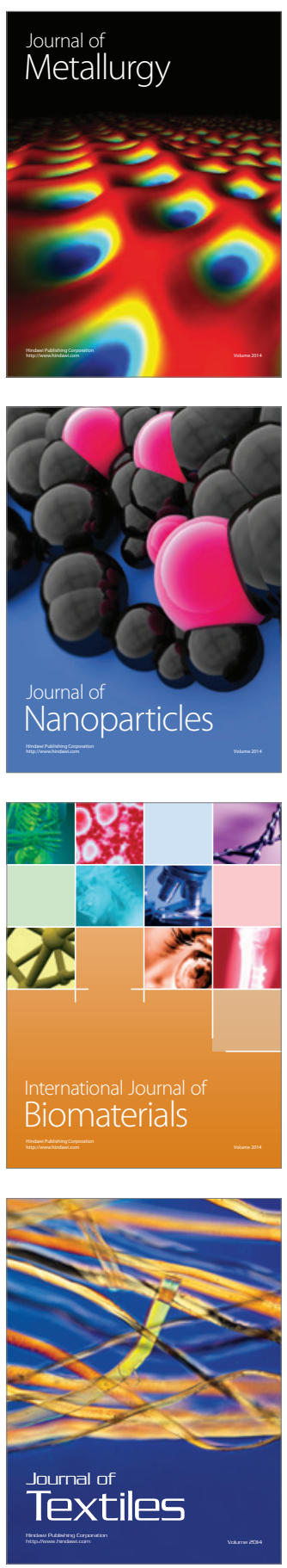